\title{
Use of Vortran Automatic Resuscitator devices as emergency backup ventilators during the COVID-19 pandemic
}

\author{
David Neilipovitz, MD, FRCPC • Andrew A. M. Ibey, M.Eng, P.Eng, CCE
}

Received: 11 January 2021/Revised: 8 May 2021 / Accepted: 18 May 2021/Published online: 7 June 2021

(C) Canadian Anesthesiologists' Society 2021

Keywords COVID $\cdot$ ventilators $\cdot$ resuscitator $\cdot$ pandemic . Vortran

\section{To the Editor,}

We describe the Vortran Automatic Resuscitator (Model RT - RespirTech PRO, K973975, Vortran Technology 1 Inc., Sacramento, CA, USA) gas-operated single-use ventilator device, which we employed to help prepare our region for the COVID-19 pandemic. The version we employed was originally purchased in preparation for potential $\mathrm{Y} 2 \mathrm{~K}$ problems at the turn of the century. As these devices were $20+$ years old, we were concerned about their safety and reliability. Updated versions have a five-year expiry recommendation for the device and tubing.

As the COVID-19 pandemic unfolded, apprehension that supplies could not be immediately replenished, along with the potential need for a large number of ventilators, prompted us to distribute these backup devices. Prior to distribution, we ensured that these devices were still operational. We randomly selected a device, set it up on a test bench supplying $100 \%$ oxygen at a rate of $15 \mathrm{~L} \cdot \mathrm{min}^{-1}$ from a wall outlet, and began ventilation on a test lung (Siemens/Maquet 1 Litre Test Lung Adult 190, Rastatt, Germany), allowing the ventilator to oscillate between 0 and $30 \mathrm{cmH}_{2} \mathrm{O}$. The device began ventilating the simulated

\section{Supplementary Information The online version contains supplementary material available at https://doi.org/10.1007/s12630- 021-02038-7.}

D. Neilipovitz, MD, FRCPC (ه) · A. A. M. Ibey, M.Eng, P.Eng, CCE

The Ottawa Hospital, University of Ottawa, Ottawa, ON, Canada

e-mail: dneilipovitz@toh.on.ca lung on 23 March 2020 and has continued to run with only one brief interruption when the simulated lung had to be replaced. As such, the device has now been functioning for more than a year (almost 9,000 hr).

The RespirTech PRO is a short-term, pneumatic, singleuse ventilator-like device that runs on a pressurized source of oxygen (pipeline or cylinder); ${ }^{1,2}$ it does not require electricity to operate. Its operation consists of adjusting two separate dials. The square dial (see eAppendix in Electronic Supplementary Material) adjusts the delivered pressure, which impacts peak pressure on inspiration and goes up to $50 \mathrm{psi}$. The round dial affects the inspiratory time thus affecting respiratory frequency. The delivered tidal volume is determined by both the inspiratory pressure and inspiratory time along with the overall respiratory compliance and resistance of the patient. As seen in the Figure, there is a rudimentary pressure manometer device.

The RespirTech PRO is essentially a pressure-controlled ventilation device. As there is no monitoring or ability to measure inspiratory volumes with the device, it requires the operator to adjust the various settings by observing the patient along with the clinical response. There is no way to add positive end-expiratory pressure to this version. If the inspiratory time is adjusted to the highest level, the device no longer cycles and can become a continuous positive airway pressure device, and the pressure can be adjusted with the inspiratory pressure dial.

We distributed three to six devices throughout our subregion and other remote locations. Their intent was to serve as a temporizing backup device (i.e., if existing resources were overwhelmed). We created an information sheet on device operation along with instructional videos (https:// www.covidottawa.com/y2kpneumaticvent). We are aware of one device being utilized that successfully oxygenated 


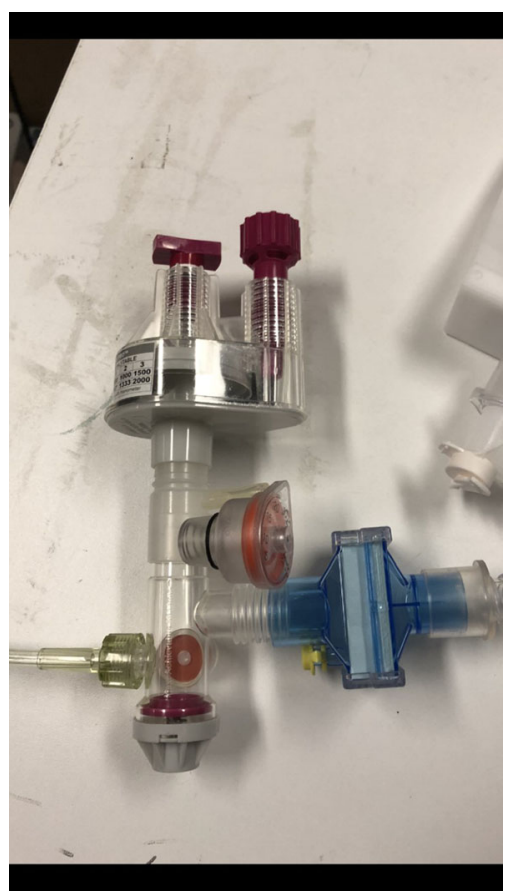

Figure Vortran Automatic Resuscitator

the patient until they were transferred to a facility where a conventional ventilator was available.

The next generation device is the $\mathrm{GO}_{2} \mathrm{VENT}^{\mathrm{TM}}$, which is predicated on the original Vortran Automatic Resuscitator design. It uses similar ventilator mechanics and includes improvements so it is compatible with magnetic resonance imaging and oxygen titration $(50-100 \%))^{3}$

We propose that these devices should serve only as emergency backups. For infection control, we recommend adding a hepafilter and using the devices in a manner consistent with a facility's bilevel positive airway pressure practice. We believe conventional devices, including those with safety features and the ability to measure delivered ventilation, are always preferred. Nevertheless, should a centre have no available ventilators, these devices could serve as emergent bridging therapy. Given these devices were $20+$ years old but still able to successfully operate for over a year is reassuring and a testament to their design.

\section{Disclosures None.}

Funding statement None.

Editorial responsibility This submission was handled by Dr. Sangeeta Mehta, Associate Editor, Canadian Journal of Anesthesial Journal canadien d'anesthésie.

\section{References}

1. Babic MD, Chatburn RL, Stoller JK. Laboratory evaluation of the Vortran Automatic Resuscitator Model RTM. Respir Care 2007; 52: 1718-27.

2. Romano $M$, Raabe $O G$, Walby $W$, Albertson TE. The stability of arterial blood gases during transportation of patients using the RespirTech PRO. Am J Emerg Med 2000; 18: 273-7.

3. U.S. Food and Drug Administration; Department of Health and Human Services; Center for Devices and Radiological Health. VORTRAN ${ }^{\circledR} \mathrm{GO}_{2}$ VENT $^{\mathrm{TM}} \mathrm{K} 162968$ approval letter, April 10, 2017. Available from URL: https://www.accessdata.fda.gov/cdrh_ docs/pdf16/K162968.pdf (accessed May 2021).

Publisher's Note Springer Nature remains neutral with regard to jurisdictional claims in published maps and institutional affiliations. 